\title{
Arsenic biotransformation by a cyanobacterium Nostoc sp. PCC $7120^{\text {is }}$
}

\author{
Xi-Mei Xue ${ }^{\text {a }}$, Yu Yan ${ }^{\text {a, b }}$, Chan Xiong ${ }^{c}$, Georg Raber ${ }^{c}$, Kevin Francesconi ${ }^{c}$, Ting Pan ${ }^{\text {a, b }}$, \\ Jun Ye ${ }^{a}$, Yong-Guan Zhu ${ }^{\text {a, d, * }}$ \\ ${ }^{a}$ Key Laboratory of Urban Environment and Health, Institute of Urban Environment, Chinese Academy of Sciences, Xiamen 361021, China \\ ${ }^{\mathrm{b}}$ University of Chinese Academy of Sciences, Beijing 100049, China \\ c Institute of Chemistry, University of Graz, Graz, 8010, Austria \\ d State Key Laboratory of Urban and Regional Ecology, Research Center for Eco-Environmental Sciences, Chinese Academy of Sciences, Beijing 100085, China
}

\section{A R T I C L E I N F O}

\section{Article history:}

Received 9 March 2017

Received in revised form

28 April 2017

Accepted 2 May 2017

Available online 18 May 2017

\section{Keywords:}

Nostoc

Arsenic

Arsenosugars

Arsenosugar phospholipids

\begin{abstract}
A B S T R A C T
Nostoc sp. PCC 7120 (Nostoc), a typical filamentous cyanobacterium ubiquitous in aquatic system, is recognized as a model organism to study prokaryotic cell differentiation and nitrogen fixation. In this study, Nostoc cells incubated with arsenite (As(III)) for two weeks were extracted with dichloromethane/ methanol $(\mathrm{DCM} / \mathrm{MeOH})$ and the extract was partitioned between water and DCM. Arsenic species in aqueous and DCM layers were determined using high performance liquid chromatography - inductively coupled plasma mass spectrometer/electrospray tandem mass spectrometry (HPLC-ICPMS/ESIMSMS). In addition to inorganic arsenic (iAs), the aqueous layer also contained monomethylarsonate (MAs(V)), dimethylarsinate $(\operatorname{DMAs}(\mathrm{V}))$, and the two arsenosugars, namely a glycerol arsenosugar (Oxo-Gly) and a phosphate arsenosugar (Oxo-PO4). Two major arsenosugar phospholipids (AsSugPL982 and AsSugPL984) were detected in DCM fraction. Arsenic in the growth medium was also investigated by HPLC/ICPMS and shown to be present mainly as the inorganic forms $\mathrm{As}(\mathrm{III})$ and $\mathrm{As}(\mathrm{V})$ accounting for $29 \%-38 \%$ and $29 \%$ $-57 \%$ of the total arsenic respectively. The total arsenic of methylated arsenic, arsenosugars, and arsenosugar phospholipids in Nostoc cells with increasing As(III) exposure were not markedly different, indicating that the transformation to organoarsenic in Nostoc was not dependent on As(III) concentration in the medium. Our results provide new insights into the role of cyanobacteria in the biogeochemical cycling of arsenic.
\end{abstract}

두 2017 Elsevier Ltd. All rights reserved.

\section{Introduction}

Arsenic is a ubiquitous and carcinogenic toxic element, and has both acute and chronic toxicity effects on humans. The bioavailability of arsenic and its resultant toxicity are influenced to a great extent by its species (Smedley and Kinniburgh, 2002; Sharma and Sohn, 2009). Inorganic arsenic, the major form of arsenic in water and soils, is transformed into organic arsenic species or in reverse in natural biological processes, and microorganisms play a critical role in arsenic biogeochemical cycle (Zhu et al., 2014; Zhang et al., 2017).

To survive in arsenic-enriched environments, organisms have evolved various mechanisms to utilize or detoxify arsenic (Stolz et al., 2006). Following the absorption of $\mathrm{As}(\mathrm{V})$ into cells via

\footnotetext{
This paper has been recommended for acceptance by Yong Sik Ok.

* Corresponding author. Institute of Urban Environment, Chinese Academy of Sciences, 1799 Jimei Road, Xiamen 361021, China.

E-mail address: ygzhu@rcees.ac.cn (Y.-G. Zhu).
}

phosphate transport systems, a two-step pathway is invoked by organisms to decrease arsenic levels in cells. $\mathrm{As}(\mathrm{V})$ is first reduced to $\mathrm{As}(\mathrm{III})$, and then $\mathrm{As}(\mathrm{III})$ is either pumped out via membrane proteins or stored in vacuoles (Tamaki and Frankenberger, 1992). Methylated arsenic species are also widely found in organisms, especially in many photosynthetic organisms (Ye et al., 2012). Although trivalent methylated arsenic, methylarsonous acid (MAs(III)) and dimethylarsinnous acid (DMAs(III)), are much more toxic than $\mathrm{As}(\mathrm{III}), \mathrm{As}(\mathrm{III})$ methylation is considered as a process of detoxification eventually producing $\operatorname{MAs}(\mathrm{V})$, DMAs(V), and trimethylarsine oxide (TMAO) (Qin et al., 2006, 2009; Yin et al., 2011). Man-made organoarsenic (e.g. herbicide, roxarsone, nitarsone, and $p$-arsanilic acid) are widely used in the agriculture, and could be biodegraded to inorganic arsenic by microbes, worsening food and water pollution (Yoshinaga and Rosen, 2014; Yoshinaga and Cai, 2011; Chen and Rosen, 2016).

Other, more complex, organoarsenic compounds such as arsenobetaine, arsenosugars and arsenolipids are also found in 
marine (Francesconi, 2005), freshwater (Miyashita et al., 2009, 2012), and terrestrial organisms (Geiszinger et al., 1998). So far, more than 20 arsenosugars have been characterized (Nischwitz and Pergantis, 2007), and arsenolipids are also now often reported in marine samples (Glabonjat et al., 2014; Rumpler et al., 2008; Taleshi et al., 2010). However, the biosynthetic processes leading to the production of arsenosugars or arsenolipids are still not well understood.

Cyanobacteria are involved in arsenic biogeochemical cycle, and have been reported to have the ability to methylate inorganic arsenic (Ye et al., 2012; Guo et al., 2016), produce arsenosugars and arsenosugar phospholipids (Xue et al., 2014a). The previous studies showed that Nostoc methylated As(III) to DMAs(V) and TMA(O) (Yin et al., 2011), demethylated MAs(V) and MAs(III) into As(III) (Yan et al., 2015), and produced Oxo-Gly (Miyashita et al., 2012). Compared to the extraction with water or nitric acid, the extraction with dichloromethane/methanol (DCM/MeOH) will divide arsenic in cells into water-soluble (such as inorganic arsenic, methylated arsenic, arsenosugars, etc) and lipid-soluble arsenic (such as arsenosugar phospholipids, arsenic-containing fatty acids, arseniccontaining hydrocarbons, etc) (Glabonjat et al., 2014). In this study, HPLC-ICPMS/ESIMS was used to analyze water-soluble and lipidsoluble arsenic species of Nostoc in order to understand arsenic biotransformation by Nostoc from multiple perspectives. The Oxo$\mathrm{PO}_{4}$ and two arsenosugar phospholipids were found in Nostoc treated with As(III). For the first time, arsenic demethylation and arsenolipid biosynthesis were found to co-occur in one organism. It has great implications for future studies aiming to fully understand arsenic transformation and fate in the environment.

\section{Materials and methods}

\subsection{Cyanobacteria culture and harvesting}

Axenic cultures of Nostoc were grown in $150 \mathrm{~mL}$ Erlenmeyer flasks containing $50 \mathrm{~mL}$ BG-11 medium without $\mathrm{NaNO}_{3}$ (Rippka et al., 1979) at $28{ }^{\circ} \mathrm{C}$ with shaking at $120 \mathrm{rpm}$ under continuous light $\left(40 \mu \mathrm{mol}\right.$ photons $\left.\mathrm{m}^{-2} \mathrm{~s}^{-1}\right)$. Nostoc cells at stationary phase (cell number remains constant during this phase) were treated with $0.1,1,10,100 \mu \mathrm{M} \mathrm{As}$ (III) for two weeks; each treatment was performed in triplicate. Nostoc was harvested by centrifuging at $4700 \mathrm{~g}$ for $15 \mathrm{~min}$ at $4{ }^{\circ} \mathrm{C}$. The sample was separated into two parts: growth medium and cells. The growth medium was filtered using syringe filters ( $0.2 \mu \mathrm{m}$ Nylon membrane) (VWR International, West Chester, PA, USA), and stored at $-80{ }^{\circ} \mathrm{C}$ until arsenic species and total arsenic analysis. The cells were transferred to $15 \mathrm{~mL}$ polypropylene tubes with screw-caps after being washed three times with cold MES buffer (Yin et al., 2011), then freeze-dried.

\subsection{Fractionation of arsenic in Nostoc}

The fractionation of arsenic in Nostoc was carried out as described in Fig. 1. About $30 \mathrm{mg}$ of freeze-dried cells were weighed (to a precision of $0.1 \mathrm{mg}$ ) directly into a centrifuge tube $(15 \mathrm{~mL}$, polypropylene), and $5 \mathrm{~mL}$ of a mixture of DCM/MeOH $(2+1, \mathrm{v} / \mathrm{v})$ was added. The mixture was extracted on a rotary wheel overnight, and centrifuged at $4754 \mathrm{~g}$ and $4{ }^{\circ} \mathrm{C}$ for $15 \mathrm{~min}$.

$0.5 \mathrm{~mL}$ of $1 \%$ aqueous $\mathrm{NH}_{4} \mathrm{HCO}_{3}$ solution was added to the supernatant $(\sim 4.5 \mathrm{~mL})$, and the mixture was gently shaken. After standing for $30 \mathrm{~min}$, the solution was separated into an aqueous layer (upper layer, $\mathrm{MeOH}$ and $\mathrm{H}_{2} \mathrm{O}$ ) and DCM-MeOH layer (lower layer). The aqueous layer was transferred to $2 \mathrm{~mL}$ Eppendorf tubes, and stored at $-80{ }^{\circ} \mathrm{C}$ for later total arsenic analysis and watersoluble arsenic species determination.

A portion of the DCM layer $(2 \mathrm{~mL})$ was applied to a $150 \times 5 \mathrm{~mm}$ glass Pasteur pipet filled with silica gel 60 (to a height of $4 \mathrm{~cm}$ ) that was pre-conditioned with $5 \mathrm{~mL}$ of $1 \%$ formic acid in acetone/MeOH $(1+1, \mathrm{v} / \mathrm{v})$. The column was washed with pure $\mathrm{MeOH}(5 \mathrm{~mL})$ firstly, then the arsenolipids were eluted with $5 \mathrm{~mL}$ of pure $\mathrm{MeOH}$ containing $1 \% \mathrm{NH}_{4} \cdot \mathrm{H}_{2} \mathrm{O}$. The arsenolipid fraction was evaporated to dryness, and stored at $4{ }^{\circ} \mathrm{C}$ until analysis. $300 \mu \mathrm{L}$ of ethanol (EtOH) were added to the arsenolipid fraction, and ultrasonicated for $30 \mathrm{~min} 200 \mu \mathrm{L}$ of the arsenolipid fractionwas used for analysis after centrifuging for $15 \mathrm{~min}$ and filtering with $0.2 \mu \mathrm{m}$ Nylon filters (ProFills, Markus Bruckner Analysentechnik, Linz, Austria).

The pellet after $\mathrm{DCM} / \mathrm{MeOH}$ extraction, dried using nitrogen stripping method, was added with $500 \mu \mathrm{L}$ of $\mathrm{H}_{2} \mathrm{O}$, sonicated for $15 \mathrm{~min}$, and the mixture subjected to repetitive freeze-thawing ( 6 cycles) before being centrifuged for $15 \mathrm{~min}$. Arsenic species and total arsenic concentration in the supernatant were analyzed. The residue after water extraction was dried for determination of total arsenic concentration.

\subsection{Determination of total arsenic concentration}

The lyophilized Nostoc (about $15 \mathrm{mg}$ ), part of all sample extracts, the residue after water extraction, and CRM 7405-a (certified reference material) were analyzed for total arsenic concentration as follows. The samples were weighed into polypropylene digest tubes $(50 \mathrm{~mL})$, and $2 \mathrm{~mL}$ of a solution of internal standards $\left(100 \mu \mathrm{g} \mathrm{L}^{-1} \mathrm{Ge}\right.$, In, Te in $1 \% \mathrm{HNO}_{3}$ ) and $2 \mathrm{~mL}$ conc. $\mathrm{HNO}_{3}$ were added. The samples were transferred to a microwave-accelerated reaction system (Mars CEM, CEM Corporation, Matthews, NC, USA), and digested according to the following temperature program: $0-10 \mathrm{~min}, 80^{\circ} \mathrm{C}$; $10-30 \mathrm{~min}, 120{ }^{\circ} \mathrm{C} ; 30-60 \mathrm{~min}, 160{ }^{\circ} \mathrm{C}$. The clear digest solutions were transferred to polypropylene tubes $(15 \mathrm{~mL})$, and diluted with Mill-Q water to $10 \mathrm{~mL}$ after being cooled to room temperature.

Determination of total arsenic concentration in the digested solutions were carried out using an Agilent $7500 \mathrm{cx}$ ICP-MS in collision cell mode (He, $5 \mathrm{~mL} \mathrm{~min}^{-1}$ ) to avoid interferences from ${ }^{40} \mathrm{Ar}^{35} \mathrm{Cl}$ on ${ }^{75} \mathrm{As}$. The digest and analytical methods were validated against the certified reference material CRM 7405-a (Hijiki), with a

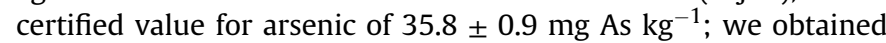
$36.2 \pm 0.8 \mathrm{mg} \mathrm{As} \mathrm{kg}^{-1}(\mathrm{n}=3)$ in this work.

\subsection{HPLC-ICPMS/ESIMSMS analysis of water-soluble arsenic species}

Anion-exchange HPLC (Agilent 1100 HPLC system) was carried out with a PRP-X100 column $(4.6 \times 150 \mathrm{~mm} ; 5 \mu \mathrm{m}$ particle size;

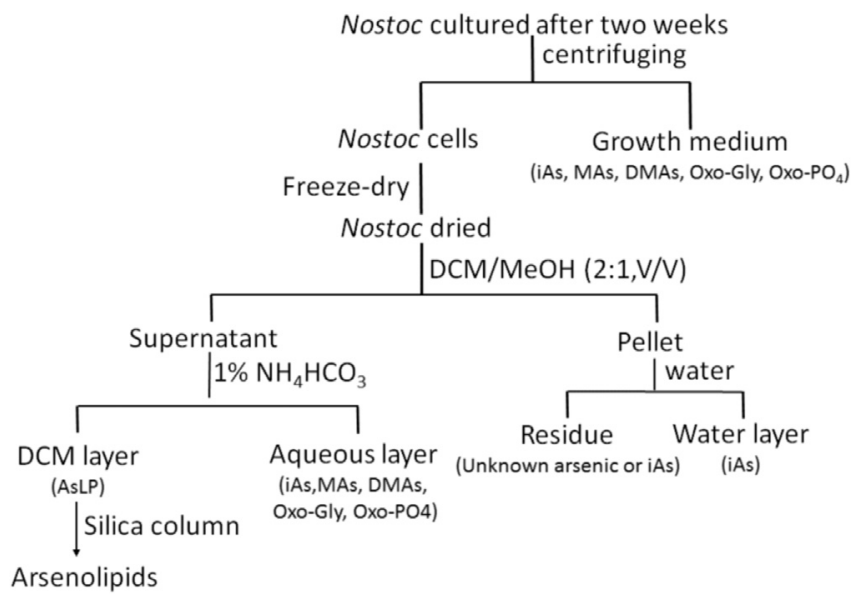

Fig. 1. The diagram of extracting arsenic compounds from Nostoc. 
Hamilton Company, Reno, Nevada, USA) and a Hamilton PEEK precolumn at $40{ }^{\circ} \mathrm{C}$, and a mobile phase of $\left(200 \mathrm{mM} \mathrm{NH}_{4} \mathrm{HCO}_{3}\right)$ under gradient elution conditions: 0-6 $\mathrm{min}, 30 \mathrm{mM}$; 6-10 $\mathrm{min}$, 30-200 mM; $10-15 \mathrm{~min}, 200 \mathrm{mM} ; 15.1-20 \mathrm{~min}, 30 \mathrm{mM}$ to reequilibrate the column prior to the next injection. The flow rate was $1 \mathrm{~mL} \mathrm{~min}^{-1}$, and the injection volume was $20 \mu \mathrm{L}$. Quantification was performed using external calibration against the mixtures of $\mathrm{As}(\mathrm{V}), \operatorname{MAs}(\mathrm{V})$ and $\operatorname{DMAs}(\mathrm{V})$. The effluent flow from the anionexchange column was split to the ICPMS (Agilent 7900) (10\%) and to the Triple Quadrupole MS System (Agilent 6460) (90\%) (Agilent Technologies, Waldbronn, Germany). Arsenic species were identified both by retention time matching experiments with standard arsenic species ( $\mathrm{As}(\mathrm{III}), \mathrm{As}(\mathrm{V}), \mathrm{MAs}(\mathrm{V}), \mathrm{DMAs}(\mathrm{V}))$, extracts of Fucus serratus containing the four most common arsenosugars (Oxo-Gly, Oxo- $\mathrm{PO}_{4}$, sulfonate arsenosugar $\left(\mathrm{Oxo}-\mathrm{SO}_{3}\right)$, sulfate arsenosugar $\left.\left(\mathrm{OxO}-\mathrm{SO}_{4}\right)\right)$ by ICPMS and protonated molecular ions by ESIMSMS.

\subsection{HPLC-ICPMS/ESIMSMS analysis of arsenolipids in Nostoc cells}

Separation was performed under reversed-phase conditions using a Shodex Asahipak C8P-50 4D column $(4.6 \times 150 \mathrm{~mm}, 5 \mu \mathrm{m}$ particle size), an aqueous solution containing $0.1 \%$ formic acid (A) and pure $\mathrm{MeOH}$ containing $0.1 \%$ formic acid (B) performed under following gradient condition: $0-20 \mathrm{~min} 50 \%-100 \% \mathrm{~B}, 20-23 \mathrm{~min}$ $100 \% \mathrm{~B}, 23.1-30 \mathrm{~min} 50 \% \mathrm{~B}$; the flow rate was $0.5 \mathrm{~mL} \mathrm{~min}^{-1}$ and the injection volume was $25 \mu \mathrm{L}$. The column effluent was split using a passive splitter with $80 \%$ being transferred directly to the ESIMSMS. The remaining $20 \%$ of the split flow was transferred to the ICPMS together with a support flow of water containing $1 \%$ formic acid and $20 \mu \mathrm{g} \mathrm{L}^{-1} \mathrm{Ge}$, In, Te $\left(0.3 \mathrm{~mL} \mathrm{~min}^{-1}\right)$ introduced through a Tpiece after the splitter. Carbon compensation was performed by continuous addition of $\mathrm{H}_{2} \mathrm{O} / \mathrm{MeOH}(7+3, \mathrm{v} / \mathrm{v})$ delivered with an integrated sample introduction system (ISIS) pump $(0.02 \mathrm{rpm})$ to ensure that a constant carbon content reached the plasma (Raber et al., 2010). Determination of arsenic in the DCM fraction was carried out by ICPMS in no gas mode, with $7 \%$ optional gas $\mathrm{O}_{2}$, and in platinum setup. ICPMS signal was recorded at $\mathrm{m} / \mathrm{z} 75\left({ }^{75} \mathrm{As}\right.$ or $\left.{ }^{40} \mathrm{Ar}{ }^{35} \mathrm{Cl}\right)$ at dwell times of $300 \mathrm{~ms}$, at $\mathrm{m} / \mathrm{z} 77\left({ }^{40} \mathrm{Ar}^{37} \mathrm{Cl}\right.$, possible chloride interference), and internal standards at $\mathrm{m} / \mathrm{z} 74\left({ }^{74} \mathrm{Ge}\right), \mathrm{m} / \mathrm{z}$ $115\left({ }^{115} \mathrm{In}\right)$, and $\mathrm{m} / \mathrm{z} 125\left({ }^{125} \mathrm{Te}\right)$ at dwell times of $100 \mathrm{~ms}$. The parameters for ESMS in the positive ion mode were as follows: gas temperature: $100{ }^{\circ} \mathrm{C}$, gas flow: $12 \mathrm{~L} \mathrm{~min}^{-1}$, nebulizer pressure: 45 psi, sheath gas temperature: $350{ }^{\circ} \mathrm{C}$, sheath gas flow: $11 \mathrm{~L} \mathrm{~min}^{-1}$, capillary voltage: $4500 \mathrm{~V}$, and nozzle voltage: $500 \mathrm{~V}$. Acquisition parameters: Fragmentor voltage $220 \mathrm{~V}$; cell acceleration 7; MRM parameters: MRM transition $\mathrm{m} / \mathrm{z} 985 / 983$ to $\mathrm{m} / \mathrm{z} 409$, collision energy 30; MRM transition $\mathrm{m} / \mathrm{z}$ 985/983 to $\mathrm{m} / \mathrm{z} 237$, collision energy 50; MRM transition $\mathrm{m} / \mathrm{z} 985 / 983$ to $\mathrm{m} / \mathrm{z} 97$, collision energy 70.

\section{Results}

\subsection{Arsenic accumulation in Nostoc cells}

Increasing arsenic concentration in the medium led to an elevation of arsenic concentration in the cells. After exposure to different concentrations of As(III) for 2 weeks, the total arsenic concentrations in Nostoc were measured, and the results showed that Nostoc had a strong ability to accumulate arsenic (Table 1), total arsenic concentrations in cells ranged from 11.3 to $1523 \mathrm{mg} \mathrm{kg}^{-1}$ (dry weight) when Nostoc was exposed to As(III) at concentrations ranging from $0.1 \mu \mathrm{M}$ to $100 \mu \mathrm{M}$. However, the concentration factors (mg As $\mathrm{kg}^{-1}$ dry mass of cells/exposure concentration in $\mathrm{mg} \mathrm{kg}^{-1}$ ) for Nostoc decreased with increasing arsenic exposure concentrations. For example, the concentration factor was 555 at $0.1 \mu \mathrm{M}$ As(III) treatment, which was markedly decreased to 75 at $100 \mu \mathrm{M}$ As(III) treatment.

\subsection{Arsenic partitioning in different fractions of Nostoc cells}

Each sample of Nostoc cells was separated into four fractions: the aqueous layer, the DCM layer, the water layer, and the residue after water extraction (Fig. 1), and total arsenic in each layer was determined (Table 1). Arsenic in the aqueous layers, consisting of inorganic arsenic, methylated arsenic, and arsenosugars (Fig. 2A), accounted for $1.7 \%-7.1 \%$ of the total arsenic accumulated by Nostoc cells exposed to As(III). The total concentration of arsenosugars in Nostoc cells with increasing As(III) exposure were not markedly different (Fig. S1). The arsenic in DCM layer which consisted mainly of arsenosugar phospholipids (Fig. 3) accounted for $0.4 \%-30 \%$ of the total arsenic concentration in cells. Inorganic arsenic which was detected in the water layer after the pellet was re-extracted with water (Fig. S2A) accounted for $9.7 \%-29.7 \%$ of the total arsenic concentration in cells (Table 1). After being extracted with DCM/ $\mathrm{MeOH}$ and water, more than half of the total arsenic still remained in the residues $\left(4.0-805 \mathrm{mg} \mathrm{kg}^{-1}\right.$ ) (Table 1$)$.

\subsection{Nostoc produced both arsenosugars and arsenosugar phospholipids}

Arsenic species in the aqueous layers were analyzed, with two arsenosugars (Oxo-Gly and Oxo- $\mathrm{PO}_{4}$ ) being observed following $\mathrm{As}(\mathrm{III})$ exposure (Fig. S3). The relative proportion of arsenosugars in total aqueous arsenic species in Nostoc cells was $0.5 \%-13 \%$ for OxoGly and $0.7 \%-8 \%$ for $\mathrm{OxO}-\mathrm{PO}_{4}$, and decreased with increasing $\mathrm{As}(\mathrm{III})$ exposure (Fig. 2A).

Arsenic-containing compounds in the DCM layers were characterized after performing a clean-up procedure with silica. HPLC/ ICPMS analysis of the fraction showed the presence of arsenolipids, and analysis using ESMSMS revealed that the $[\mathrm{M}+\mathrm{H}]^{+}$of two main arsenic-containing compounds were 983 and 985 (Fig. 3). The chromatographic behavior was the same as that reported previously for arsenosugar phospholipids $\left(\mathrm{C}_{47} \mathrm{H}_{88} \mathrm{O}_{14} \mathrm{AsP}\right.$ (AsSugPL982) and $\mathrm{C}_{47} \mathrm{H}_{90} \mathrm{O}_{14} \mathrm{AsP}$ (AsSugPL984) in Synechocystis sp. PCC 6803 (Xue et al., 2014a) and brown macroalgae (García-Salgado et al., 2012). Fig. 4 shows the structures of arsenosugars and arsenosugar phospholipids produced by Nostoc.

\subsection{Arsenic species in the growth medium}

Arsenic species in the growth medium with and without Nostoc incubation were determined after incubation with $\mathrm{As}(\mathrm{III})$ for 2 weeks (Fig. 2B and Fig. S2B). In the growth medium with Nostoc incubation, inorganic arsenic was the main arsenic species As(III) and $\mathrm{As}(\mathrm{V})$ accounting for $29 \%-38 \%$ and $29 \%-57 \%$ of the total arsenic respectively. The contributions of organoarsenic including DMAs and arsenosugars in the medium decreased with increasing As(III) exposure (Fig. 2B). About 16\% of total arsenic in the medium containing 0.1 or $1 \mu \mathrm{M}$ As(III) were DMAs and arsenosugars. While DMAs and arsenosugars accounted for $4 \%$ and $1.3 \%$ of total arsenic in the medium containing $10 \mu \mathrm{M}$ As(III). Furthermore, traces of DMAs and Oxo- $\mathrm{PO}_{4}$ were detected in the medium containing $100 \mu \mathrm{M}$ As(III) (Fig. 2B). In the medium without Nostoc incubation (as the control), inorganic arsenic species alone were detected, and a certain amount of $\mathrm{As}(\mathrm{III})$ was oxidated into $\mathrm{As}(\mathrm{V})$ in the air after two weeks (Fig. S2B).

\section{Discussion}

Freshwater cyanobacteria can produce arsenosugar 
Table 1

Total arsenic concentrations of Nostoc cells treated with indicated concentrations of As(III).

\begin{tabular}{|c|c|c|c|c|c|}
\hline \multirow[t]{2}{*}{ Treatment As(III) $(\mu \mathrm{M})$} & \multirow[t]{2}{*}{ Total As (mg kg $\left.{ }^{-1}\right)$} & \multicolumn{2}{|c|}{ DCM/MeOH supernatant } & \multicolumn{2}{|l|}{$\mathrm{DCM} / \mathrm{MeOH}$ pellet } \\
\hline & & DCM layer $\left(\mathrm{mg} \mathrm{kg}^{-1}\right)$ & aqueous layer $\left(\mathrm{mg} \mathrm{kg}^{-1}\right)$ & Residue ( $\mathrm{mg} \mathrm{kg}^{-1}$ ) & Water layer $\left(\mathrm{mg} \mathrm{kg}^{-1}\right)$ \\
\hline 0.1 & $11.3 \pm 1.8$ & $2.9 \pm 0.7$ & $0.8 \pm 0.1$ & $4.0 \pm 0.5$ & $1.1 \pm 0.3$ \\
\hline 1 & $101 \pm 6$ & $4.3 \pm 1.3$ & $2.8 \pm 0.1$ & $54.0 \pm 3.8$ & $17.3 \pm 0.5$ \\
\hline 10 & $225 \pm 19$ & $4.4 \pm 0.7$ & $8.4 \pm 1.4$ & $134 \pm 4.7$ & $67.2 \pm 7.2$ \\
\hline 100 & $1523 \pm 315$ & $5.2 \pm 0.8$ & $25.5 \pm 2.9$ & $805 \pm 112$ & $396 \pm 72$ \\
\hline
\end{tabular}

The amount of arsenic is expressed as $\mathrm{mg} \mathrm{kg}^{-1}$ (dry mass). The results are shown as mean \pm standard deviation from triplicate culturing samples.

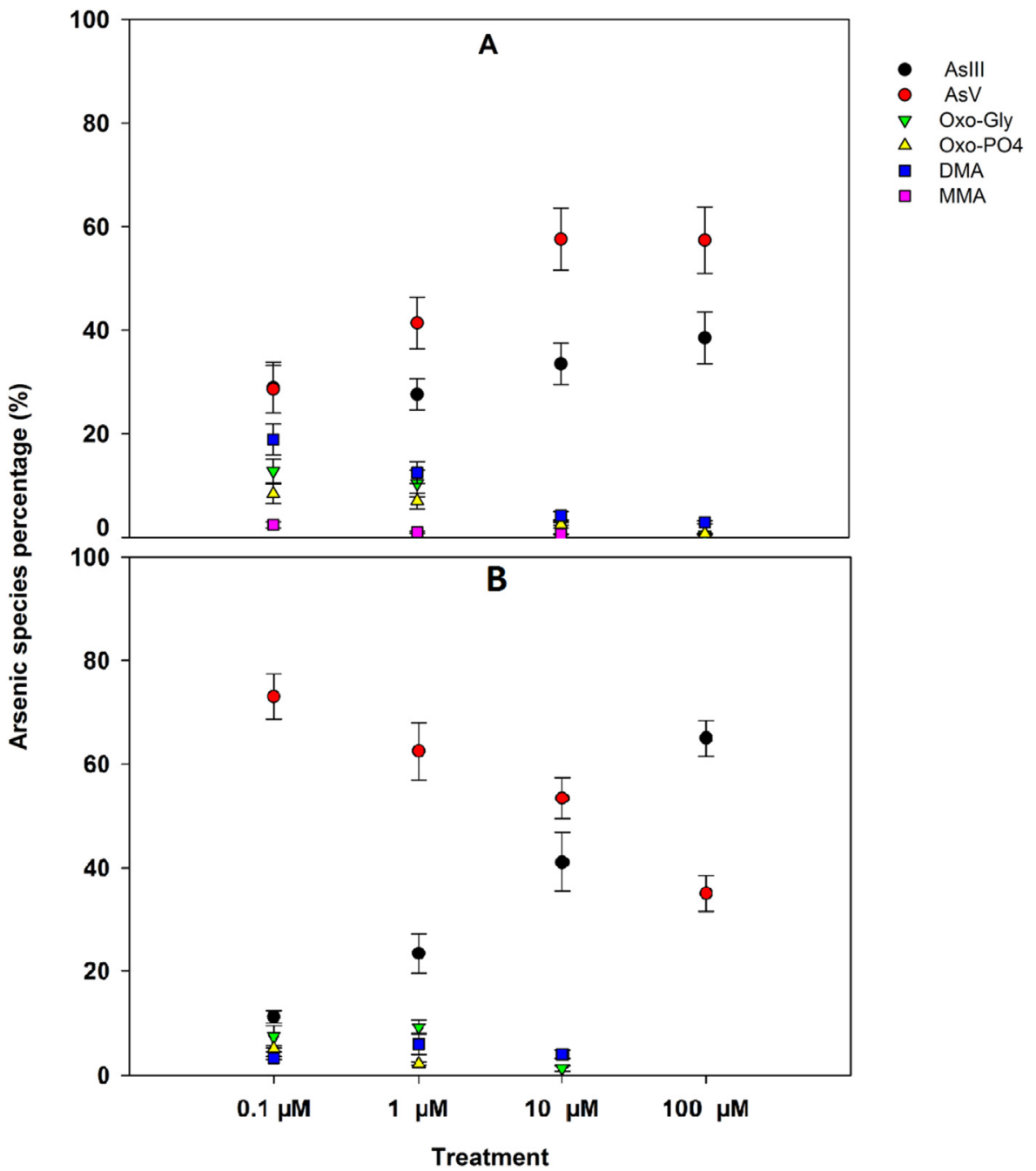

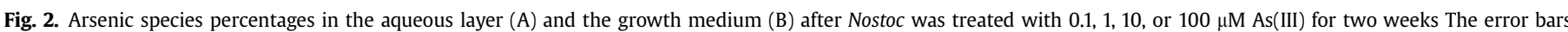
represent the standard error of three independent culture experiments.

phospholipids. Two species of arsenosugar phospholipids, AsSugPL982 and AsSugPL984, as previously characterized in Synechocystis sp. PCC 6803 (Xue et al., 2014a), were identified in Nostoc treated with As(III) for two weeks. In contrast to other studies (Yin et al., 2011; Miyashita et al., 2012), our study found that Nostoc cells exposed to $\mathrm{As}(\mathrm{III})$ produced $\mathrm{Oxo}-\mathrm{PO}_{4}$ and arsenosugar phospholipids. The discrepancy in the results from Nostoc could be related to differences in treatment time and sample extraction methods. Miyashita et al. (2012) treated Nostoc cells with As(V) for 24 h, and found that Oxo-Gly alone was present in Nostoc extracts obtained by sonicating the cells with water. Moreover, the extraction yield was generally around $100 \%$ of total arsenic suggesting that arsenolipids were not produced by the Nostoc cells during the $24 \mathrm{~h}$ exposure to $\mathrm{As}(\mathrm{V})$. Freshwater organisms, including the green algae Cladophora glomerata from the Hayakawa River and Chlamydomonas reinhardtii incubated with $\mathrm{As}(\mathrm{V})$ for 3 days, were considered to possess water-unextractable or lipid-soluble arsenic species to some extent because the extraction yields of the water-soluble arsenic from the alga were quite low (16\% for C. glomerata, $32 \%$ for C. reinhardtii) (Miyashita et al., 2009). In Yin's work (2011) with Nostoc cultured with As(III), arsenic-containing compounds in cells were extracted using $1 \% \mathrm{HNO}_{3}$ and microwave heating, treatment that would likely degrade arsenosugars (Nischwitz and Pergantis, 2007) and arsenosugar phospholipids. 

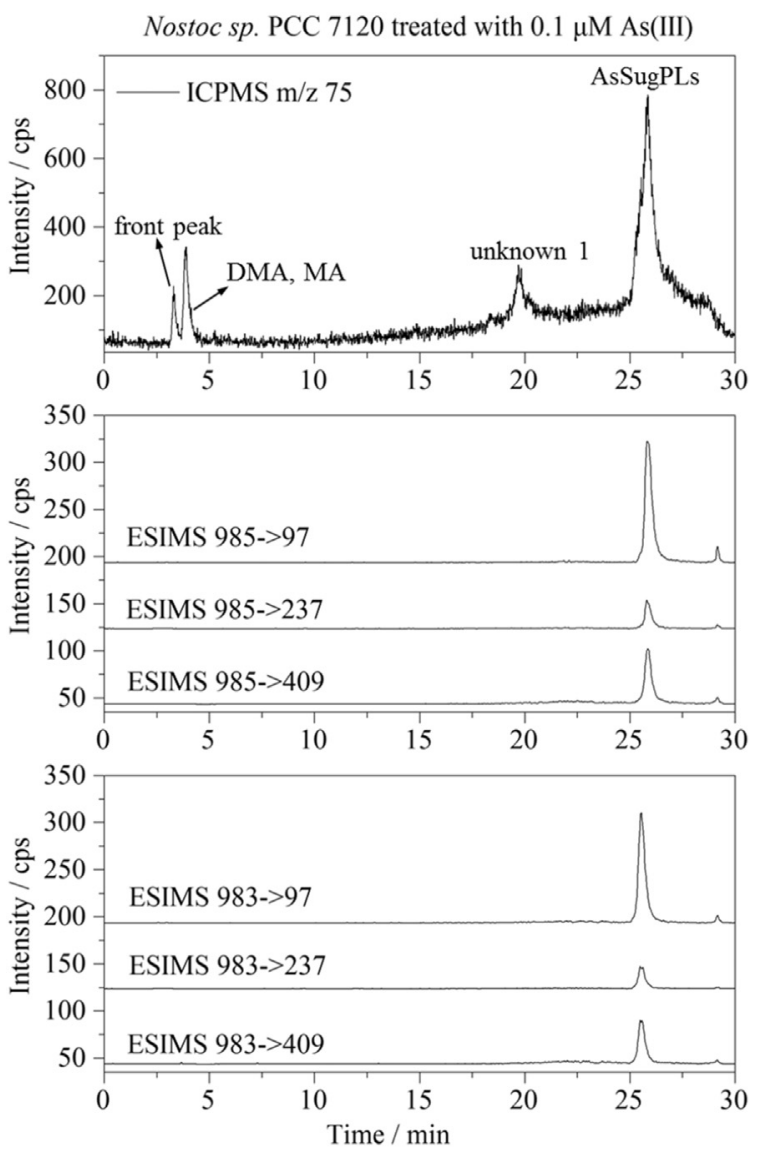

Fig. 3. HPLC/mass chromatograms of the lipid extract (post-silica column) of Nostoc. ICPMS detection at $\mathrm{m} / \mathrm{z} 75$ (arsenic-selective) and represent ions selected on $\mathrm{m} / \mathrm{z} 983$ $\left(\mathrm{RT}=25.6 \mathrm{~min} ; \mathrm{C}_{47} \mathrm{H}_{88} \mathrm{O}_{14} \mathrm{AsP} \mathrm{H}^{+}\right)$and $985\left(\mathrm{RT}=26.1 \mathrm{~min} ; \mathrm{C}_{47} \mathrm{H}_{90} \mathrm{O}_{14} \mathrm{AsP} \mathrm{H}^{+}\right)$, respectively. The parameters for ESMS in the positive ion mode were described in Materials and Methods.

Multiple arsenic speciation biotransformation pathways cooccur in Nostoc. Microbes have evolved various mechanisms to utilize or detoxify arsenic. Known mechanisms include arsenic redox changes, arsenic methylation and demethylation, As(III) efflux, and the production of complex organoarsenic. The previous proteomics analysis of Nostoc under $\mathrm{As}(\mathrm{V})$ stress showed that the expression of two genes, alr1097 (encoding an As(III) efflux protein; arsB) and alr1105 (encoding an $\mathrm{As}(\mathrm{V})$ reductase; $\operatorname{ars} C$ ) (Pandey et al., 2013), was up-regulated (Pandey et al., 2012), illustrating that Nostoc was capable of performing $\mathrm{As}(\mathrm{V})$ uptake, $\mathrm{As}(\mathrm{V})$ reduction, and As(III) excretion. Yin et al. (2011) investigated the ability of arsenic methylation by Nostoc and arsenic (III) S-adenosylmethionine methyltransferase (ArsM) from Nostoc by chemotrapping volatile TMAs(III). Moreover, our other study showed that Nostoc was able to demethylate MAs(III) rapidly to As(III) using ArsI that is a C.As lyase responsible for MAs(III) demethylation, and also could demethylate $\operatorname{MAs}(\mathrm{V})$ slowly to As(III) (Yan et al., 2015), suggesting that $\operatorname{MAs}(\mathrm{V})$ reduction and $\operatorname{MAs}(\mathrm{III})$ demethylation occurred in Nostoc. However, MAs(III) oxidation in Nostoc cannot be regarded to be catalyzed by an enzyme because ArsH homologous compound oxidizing MAs(III) (Chen et al., 2015a) was not found via blasting against the Nostoc proteome with ArsH of Synechocystis sp. PCC 6803 (Xue et al., 2014b), and we did not ensure that there was As(III) oxidation catalyzed by As(III) oxidase in Nostoc because most of $\mathrm{As}(\mathrm{III})$ in the culture medium was oxidized by oxygen after long time culture (Fig. S2B) and there was not As(III) oxidase identified in Nostoc. In addition, Nostoc was found to produce low quantities of arsenosugars and arsenolipids (Table 1 ).

An abbreviated biosynthesis pathway of arsenosugar phospholipids in Nostoc was hypothesized as described in Fig. 5. The methyl groups from S-adenosyl-L-methionine (SAM) are transferred to $\mathrm{As}(\mathrm{III})$ (which is absorbed directly by cells or arises from $\mathrm{As}(\mathrm{V})$ reduced by ArsC), by ArsM to produce trivalent methylated arsenic. Some of MAs(III) and DMAs(III) bound to ArsM are further methylated into DMAs(III) and TMAs(III). In addition, the adenosyl group from SAM is transferred to DMAs(III) falling off ArsM to generate the key intermediate of arsenosugar synthesis, namely dimethylarsinyladenosine (AsAd). AsAd undergoes glycosidation to produce Oxo-Gly which acts as a precursor to Oxo- $\mathrm{PO}_{4}$ produced later by cyanobacteria. Finally, fatty acids were added to $\mathrm{Oxo}-\mathrm{PO}_{4}$ to produce arsenosugar phospholipids by unknown enzymes.

Up to now, arsenic methylation is the most thoroughly studied arsenic biotransformation pathway. Cullen et al. (1994, 1995) verified that SAM was the methyl donor in the arsenic biological methylation in a marine alga Polyphysa peniculus and a microorganism Apiotrichum humicola by adding L-methionine-methyl-d3 in the culture medium. Marapakala et al. (2012) applied protein fluorescence of a single-tryptophan mutant to report the binding rate of trivalent arsenic species with ArsM from the thermophilic eukaryotic alga Cyanidioschyzon sp. 5508, and analyzed the crystal structures of co-crystallizing ArsM with the aromatic arsenicals PhAs(III) or Rox (III) successively (Marapakala et al., 2015). A model was proposed for the catalytic mechanism of ArsMs in which the products were maintained in the trivalent state by utilizing four conserved cysteine residues of ArsM in a disulfide-bond cascade, and DMAs(III) was accumulated as the principal product (Marapakala et al., 2015). The current results with other ArsMs, such as from Methanosarcina acetivorans C2A (Wang et al., 2014) and Spirulina platensis (Guo et al., 2016), can be explained by the above model. Moreover, part of DMAs(III) bound to ArsM was
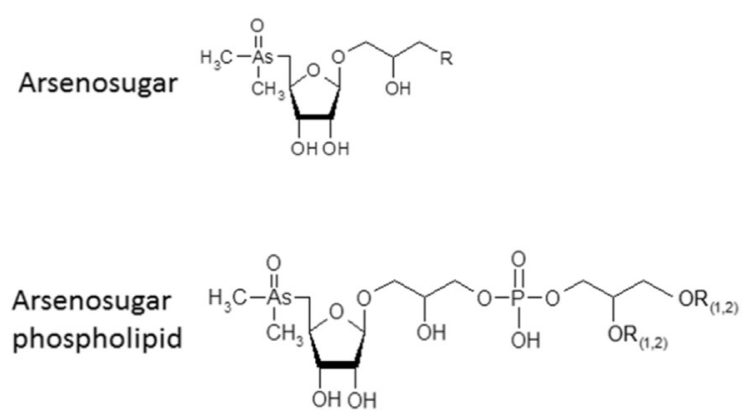
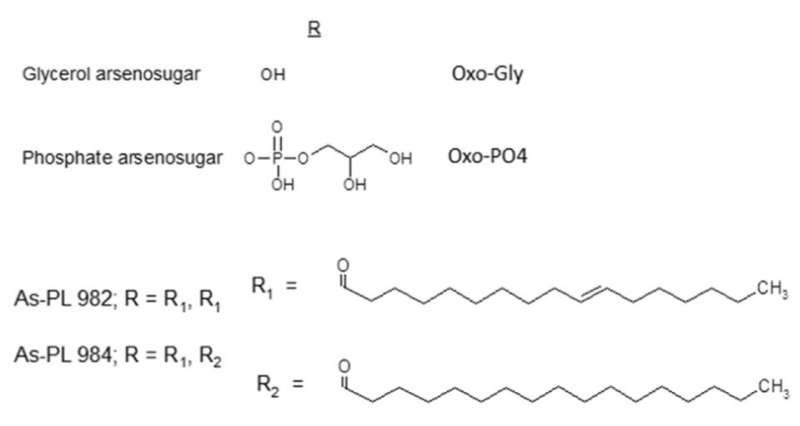

Fig. 4. The structures of arsenosugars and arsenosugar phospholipids found in Nostoc. 


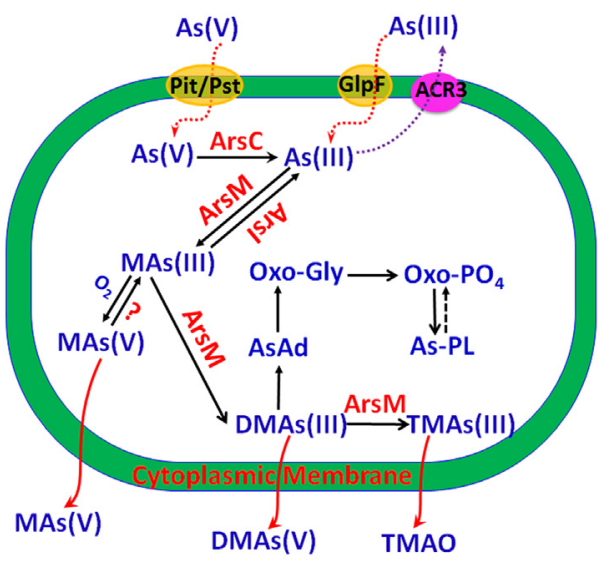

Fig. 5. Arsenic metabolism and potential biosynthetic pathways of arsenosugar phospholipids in Nostoc.

further methylated into TMA (III) (Qin et al., 2006, 2009; Yin et al., 2011). Since arsenosugars (Oxo-Gly, Oxo- $\mathrm{PO}_{4}$, and Oxo-SO 3 ) were found in a freshwater green alga Chlorella vulgaris exposed to $\mathrm{As}(\mathrm{V})$ (Murray et al., 2003), a freshwater unicellular green alga C. reinhardtii (Miyashita et al., 2011), freshwater cyanobacteria Nostoc and Synechocystis sp. PCC 6803 (Miyashita et al., 2012) were used to carry out short-term experiments (up to $24 \mathrm{~h}$ ) to uncover the detailed arsenosugar biosynthesis processes in cells. In this study, Nostoc was treated with As(III) for two weeks. The Oxo-PO which was not found in Nostoc incubated with $\mathrm{As}(\mathrm{V})$ for $24 \mathrm{~h}$ (Miyashita et al., 2012), was detected in Nostoc incubated with As(III) for two weeks. Combining with the results that Nostoc can produce arsenosugar phospholipids, we proposed that the Oxo- $\mathrm{PO}_{4}$ biosynthesis started from Oxo-Gly, and Oxo- $\mathrm{PO}_{4}$ was the precursor to arsenosugar phospholipids. However, the further evidences of molecular biology will be needed to unravel the biosynthesis process of arsenosugar phospholipids.

For the first time, arsenic demethylation and arsenolipid biosynthesis were found to be co-occurring in one organism. The more toxic MAs(III) is considerably as a transient intermediate of arsenic methylation involved in arsenic detoxification (Qin et al., 2006). When more MAs(III) resistance genes including arsI (Yoshinaga and Rosen, 2014), arsH (Chen et al., 2015a), and arsP (Chen et al., 2015b) were identified, MAs(III) was proposed to be a primordial antibiotic (Li et al., 2016). The reason of coexistence of two opposite arsenic metabolism pathway, demethylation and methylation, is unknown (Yan et al., 2017). Moreover, Synechocystis sp. PCC 6803 and Nostoc matched marine algae by being able to produce arsenosugar phospholipids, but the freshwater cyanobacteria phospholipids contained saturated and unsaturated 17-carbon fatty acid groups, instead of the palmitic acid derivatives identified in marine alga (Morita, 1988; García-Salgado et al., 2012; Raab et al., 2013). Arsenic-containing hydrocarbons, which have been identified in four species of marine algae (García-Salgado et al., 2012; Glabonjat et al., 2014; Petursdottir et al., 2016), were not detected in the cyanobacteria (Xue et al., 2014a). More work is required to determine the reasons for these differences between arsenolipids from freshwater organisms and marine organisms and the evolution of arsenic demethylation in Nostoc.

In summary, our study revealed that the model organism cyanobacterium Nostoc can produce $\mathrm{OxO}-\mathrm{PO}_{4}$ and arsenosugar phospholipids when exposed to As(III), and the production of complex organoarsenic and arsenic demethylation co-exist in Nostoc. Moreover, we proposed the biosynthesis pathway of arsenosugar phospholipids in Nostoc. These results provide new insights into the function of cyanobacteria in arsenic biogeochemical cycle. Future studies will focus on identifying and characterizing other unknown genes encoding enzymes involved in arsenic biotransformation using Nostoc as an experimental model organism.

\section{Acknowledgments}

Our research is supported by 1 ) the National Natural Science Foundation of China, China (21507125), 2) the National Key Research and Development Program of China, China (2016YFD0800706), and 3) the Austrian Science Fund project, Austria (23761-N17).

\section{Appendix A. Supplementary data}

Supplementary data related to this article can be found at http:// dx.doi.org/10.1016/j.envpol.2017.05.005.

\section{References}

Chen, J., Rosen, B.P., 2016. Organoarsenical biotransformations by Shewanella putrefaciens. Environ. Sci. Technol. 50, 7956-7963.

Chen, J., Bhattacharjee, H., Rosen, B.P., 2015a. ArsH is an organoarsenical oxidase that confers resistance to trivalent forms of the herbicide monosodium methylarsenate and the poultry growth promoter roxarsone. Mol. Microbiol. 96, $1042-1052$.

Chen, J., Madegowda, M., Bhattacharjee, H., Rosen, B.P., 2015b. ArsP: a methylarsenite efflux permease. Mol. Microbiol. 98, 625-635.

Cullen, W.R., Li, H., Pergantis, S.A., Eigendorf, G.K., Harrison, L.G., 1994. The methylation of arsenate by a marine alga Polyphysa peniculus in the presence of L-methionine-methyl-d3. Chemosphere 28, 1009-1019.

Cullen, W.R., Li, H., Pergantis, S.A., Eigendorf, G.K., Mosi, A.A. 1995. Arsenic biomethylation by the microorganism Apiotrichum humicola in the presence of $1-$ methionine-methyl-d3. Appl. Organomet. Chem. 9, 507-515.

Francesconi, Kevin A., 2005. Current perspectives in arsenic environmental and biological research. Environ. Chem. 2, 141-145.

García-Salgado, S., Raber, G., Raml, R., Magnes, C., Francesconi, K.A., 2012. Arsenosugar phospholipids and arsenic hydrocarbons in two species of brown macroalgae. Environ. Chem. 9, 63-66.

Geiszinger, A., Goessler, W., Kuehnelt, D., 1998. Determination of arsenic compounds in earthworms. Env. Sci. Technol. 32, 2238-2243.

Glabonjat, R.A., Raber, G., Jensen, K.B., Ehgartner, J., Francesconi, K.A., 2014. Quantification of arsenolipids in the certi fi ed reference material NMIJ 7405 - a (Hijiki) using HPLC/mass spectrometry after chemical derivatization. Anal. Chem. 86, 10282-10287.

Guo, Y., Xue, X., Yan, Y., Zhu, Y., Yang, G., Ye, J., 2016. Arsenic methylation by an arsenite S-adenosylmethionine methyltransferase from Spirulina platensis. J. Environ. Sci. 49, 162-168.

Li, J., Pawitwar, S.S., Rosen, B.P., 2016. The organoarsenical biocycle and the primordial antibiotic methylarsenite. Metallomics 8, 1047-1055.

Marapakala, K., Qin, J., Rosen, B.P., 2012. Identification of catalytic residues in the As(III) S-adenosylmethionine methyltransferase. Biochemistry 51, 944-951.

Marapakala, K., Packianathan, C., Ajees, A.A., Dheeman, D.S., Sankaran, B. Kandavelu, P., Rosen, B.P., 2015. A disulfide-bond cascade mechanism for arsenic(III) S-adenosylmethionine methyltransferase. Acta Crystallogr. Sect. D. Biol. Crystallogr. 71, 505-515.

Miyashita, S., Shimoya, M., Kamidate, Y., Kuroiwa, T., Shikino, O., Fujiwara, S., Francesconi, K.A., Kaise, T., 2009. Rapid determination of arsenic species in freshwater organisms from the arsenic-rich Hayakawa River in Japan using HPLC-ICP-MS. Chemosphere 75, 1065-1073.

Miyashita, S., Fujiwara, S., Tsuzuki, M., Kaise, T., 2011. Rapid biotransformation of arsenate into oxo-arsenosugars by a freshwater unicellular green alga, Chlamydomonas reinhardtii. Biosci. Biotechnol. Biochem. 75, 522-530.

Miyashita, S.I., Fujiwara, S., Tsuzuki, M., Kaise, T., 2012. Cyanobacteria produce arsenosugars. Environ. Chem. 9, 474-484.

Morita, M., Y.S, 1988. Isolation and identification of arseno-lipid from a brown alga, Undaria pinnatifida (Wakame). Chemosphere 1147.

Murray, L.A., Raab, A., Marr, I.L., Feldmann, J., 2003. Biotransformation of arsenate to arsenosugars by Chlorella vulgaris. Appl. Organomet. Chem. 17, 669-674.

Nischwitz, V., Pergantis, S.A., 2007. Mapping of arsenic species and identification of a novel arsenosugar in giant clams Tridacna maxima and Tridacna derasa using advanced mass spectrometric techniques. Environ. Chem. 4, 187-196.

Pandey, S., Rai, R., Rai, L.C., 2012. Proteomics combines morphological, physiologica and biochemical attributes to unravel the survival strategy of Anabaena sp. PCC7120 under arsenic stress. J. Proteomics 75, 921-937.

Pandey, S., Shrivastava, A.K., Rai, R., Rai, L.C., 2013. Molecular characterization of Alr1105 a novel arsenate reductase of the diazotrophic cyanobacterium 
Anabaena sp. PCC7120 and decoding its role in abiotic stress management in Escherichia coli. Plant Mol. Biol. 83, 417-432.

Petursdottir, A.H., Fletcher, K., Gunnlaugsdottir, H., Krupp, E., Kupper, F.C. Feldmann, J., 2016. Environmental effects on arsenosugars and arsenolipids in Ectocarpus (Phaeophyta). Environ. Chem. 13, 21-33.

Qin, J., Rosen, B.P., Zhang, Y., Wang, G., Franke, S., Rensing, C., 2006. Arsenic detoxification and evolution of trimethylarsine gas by a microbial arsenite Sadenosylmethionine methyltransferase. Proc. Natl. Acad. Sci. U. S. A. 103, 2075-2080.

Qin, J., Lehr, C.R., Yuan, C., Le, X.C., McDermott, T.R., Rosen, B.P., 2009. Biotransformation of arsenic by a Yellowstone thermoacidophilic eukaryotic alga. Proc. Natl. Acad. Sci. U. S. A. 106, 5213-5217.

Raab, A., Newcombe, C., Pitton, D., Ebel, R., Feldmann, J., 2013. Comprehensive analysis of lipophilic arsenic species in a brown alga (Saccharina latissima). Anal. Chem. 85, 2817-2824.

Raber, G., Raml, R., Goessler, W., Francesconi, K.A., 2010. Quantitative speciation of arsenic compounds when using organic solvent gradients in HPLC-ICPMS. J. Anal. At. Spectrom. 25 (4), 570.

Rippka, R., Deruelles, J., Waterbury, J.B., Herdman, M., Stanier, R.Y., 1979. Generic assignments, strain histories and properties of pure cultures of cyanobacteria. J. Gen. Microbiol. 111, 1-61.

Rumpler, A., Edmonds, J.S., Katsu, M., Jensen, K.B., Goessler, W., Raber, G., Gunnlaugsdottir, H., Francesconi, K.A., 2008. Arsenic-containing long-chain fatty acids in cod-liver oil: a result of biosynthetic infidelity? Angew. Chem. Int. Ed. 47, 2665-2667.

Sharma, V.K., Sohn, M., 2009. Aquatic arsenic: toxicity, speciation, transformations, and remediation. Environ. Int. 35, 743-759.

Smedley, P.L., Kinniburgh, D.G., 2002. A review of the source, behaviour and distribution of arsenic in natural waters. Appl. Geochem. 17, 517-568.

Stolz, J.F., Basu, P., Santini, J.M., Oremland, R.S., 2006. Arsenic and selenium in microbial metabolism. Annu. Rev. Microbiol. 60, 107-130.

Taleshi, M.S., Edmonds, J.S., Goessler, W., Ruiz-Chancho, M.J., Raber, G., Jensen, K.B.,
Francesconi, K.A., 2010. Arsenic-containing lipids are natural constituents of sashimi tuna. Environ. Sci. Technol. 44, 1478-1483.

Tamaki, S., Frankenberger, W.T.J., 1992. Environmental biochemistry of arsenic. Rev. Environ. Contam. Toxicol. 124, 79-110.

Wang, P.P., Sun, G.X., Zhu, Y.G., 2014. Identification and characterization of arsenite methyltransferase from an archaeon, Methanosarcina acetivorans C2A. Environ. Sci. Technol. 48, 12706-12713.

Xue, X.M., Raber, G., Foster, S., Chen, S.C., Francesconi, K.A., Zhu, Y.G., 2014a. Biosynthesis of arsenolipids by the cyanobacterium Synechocystis sp. PCC 6803. Environ. Chem. 11, 506-513.

Xue, X.M., Yan, Y., Xu, H.J., Wang, N., Zhang, X., Ye, J., 2014b. ArsH from Synechocystis sp. PCC 6803 reduces chromate and ferric iron. FEMS Microbiol. Lett. 356, 105-112.

Yan, Y., Ye, J., Xue, X.M., Zhu, Y.G., 2015. Arsenic demethylation by a C As lyase in cyanobacterium Nostoc sp. PCC 7120. Environ. Sci. Technol. 49, 14350-14358.

Yan, Y., Xue, X.M., Guo, Y.Q., Zhu, Y.G., Ye, J., 2017. Co-expression of cyanobacteria genes for arsenic methylation and demethylation in Escherichia coli offers insights into arsenic resistance. Front. Microbiol. 8, 1-9.

Ye, J., Rensing, C., Rosen, B.P., Zhu, Y.G., 2012. Arsenic biomethylation by photosynthetic organisms. Trends Plant Sci. 17, 155-162.

Yin, X.X., Chen, J., Qin, J., Sun, G.X., Rosen, B.P., Zhu, Y.G., 2011. Biotransformation and volatilization of arsenic by three photosynthetic cyanobacteria. Plant Physiol. $156,1631-1638$.

Yoshinaga, M., Rosen, B.P., 2014. A C as lyase for degradation of environmental organoarsenical herbicides and animal husbandry growth promoters. Proc. Natl. Acad. Sci. U. S. A. 111, 7701-7706.

Yoshinaga, M., Cai, Y.R.B., 2011. Demethylation of methylarsonic acid by a microbial community. Env. Microbiol. 13, 1205-1215.

Zhang, S., Williams, P.N., Luo, J., Zhu, Y., 2017. Microbial mediated arsenic biotransformation in wetlands. Front. Environ. Sci. Eng. 11 (1), 1-11.

Zhu, Y.G., Yoshinaga, M., Zhao, F.J., Rosen, B.P., 2014. Earth abides arsenic biotransformations. Annu. Rev. Earth Planet. Sci. 42, 443-467. 